\title{
Proceeding
}

Supplementary Issue: Rio 2016 Olympic Games Second Anniversary Special Edition. Olympic Studies Forum, 2-3 October 2018.

Federal University of Espirito Santo, (Vitória - Espirito Santo), Brazil

\section{The three dimension model for grassroots sport: An opportunity to transform coaches professional practice with the use of Olympic Values Education Program in Puerto Rico}

\author{
RAMÓN LUIS ALVAREZ FELICIANO \\ Olympic Studies Center \& Kinesiology Department, University of Puerto Rico, Mayagüez Campus, Puerto \\ Rico
}

\begin{abstract}
Sports in an important cultural expression in human society. In Puerto Rico has been a cultural value for all society2. Benefits for sports participant has been documented in physical, psychological and social dimension ${ }^{23}$. But sports grant opportunity in the Island has provoke a high performance approach toward grassroots sports. This traditional pyramidal approach has been identified with one of the sport dropout causes. Therefore sedentarism and eventually child obesity has been related to sport dropout. A professional practice paradigm shift is needed in the grassroots sports to a more holistic approach. In this document a Three Dimension Model (3DM) is been suggested as a strategy to transform the actual Puerto Rico grassroots sports coaches medal approach. The 3DM is the first effort to formally state a "wake up call" toward the high performance approach in Puerto Rico's grassroots sports. The model suggest the combination of Balyi's Long-Term Athlete Development ${ }^{4}$ with the Olympic Values Education Program $(\text { OVEP })^{15}$ to proper impact body and mind of young athletes. Keywords: Sport; Grassroot sport; Olympic values.
\end{abstract}

\section{Cite this article as:}

Álvarez, R.L. (2019). The three dimension model for grassroots sport: An opportunity to transform coaches professional practice with the use of Olympic Values Education Program in Puerto Rico. Journal of Human Sport and Exercise, 14(3proc), S328-S335.

doi:https://doi.org/10.14198/jhse.2019.14.Proc3.06

Corresponding author. Olympic Studies Center \& Kinesiology Department, University of Puerto Rico, Mayagüez Campus, Puerto Rico.

E-mail: Ramón.alvarez3@upr.edu

Supplementary Issue: Rio 2016 Olympic Games Second Anniversary Special Edition. Olympic Studies Forum, 2-3 October 2018. Federal University of Espírito Santo, (Vitória - Espírito Santo), Brazil.

JOURNAL OF HUMAN SPORT \& EXERCISE ISSN 1988-5202

(c) Faculty of Education. University of Alicante

doi:10.14198/jhse.2019.14.Proc3.06

S328 | $2019 \mid$ Proc3 | VOLUME 14

(C) 2019 University of Alicante 


\section{THE IMPORTANCE OF SPORT IN THE SOCIETY}

Sports have been a natural and common cultural expression in the human being since the beginning of times. Evidence of different type of sports has been documented since ancient times. Celebration and religious rituals was express thru sports festivals and competitions. Ancients Olympic Games date from the year 767 B.C. and evidence of other sports games are from earlier years. ${ }^{8}$

In contemporary society sports is an important part. Professional sports, Olympic Games and other form of physical activity have been established as "an important socialization agency" (Hodge and Lonsdale, 2011). Authors state "sport has a meaningful role to play in this regard". As Morales Guzman (2001) state cite in Alvarez (2015) "sports is a human expression which involve a huge number of people, including participants and spectators". Merkel (2013) reports that in the US 75\% of every family "with school-age children have at least one child" in organize sports.

"Sports is a relevant cultural expression in the Puerto Rico society".,2 8 Puerto Rico international participation start in 1930 at the Central American and Caribbean Games in La Habana Cuba and in the Olympic games in 1948 (London). ${ }^{8}$ One of the important dimensions of sport in Puerto Rico is society mobility thru ought college sports grants. As the Economic Mobility Pathways (2016) projects establish. Education is one of the pathways pillars to society mobility. Found in 1929 Puerto Rico has a 19 college's sports league named "Liga Atlética Interuniversitaria de Puerto Rico y las Islas Vírgenes" which offer full or half scholarship in 18 sports. Therefore grass root sports coaches and parents focus their sports training toward a high performance approach as strategy to obtain a college scholarship. Merkel (2013) connect this approach with "controversial topics, such as early specialization, identification of elite players, trained and untrained coaches, increasing injury rates and moral issues of character and sportsmanship".

\section{HIGH PERFORMANCE APPROACH TOWARD GRASS ROOT SPORT}

The high performance approach toward grass roots sports is been debate in the sports scientific community. Studies have found high levels of sport dropout in early sports specialization participants. Merkel (2013) identify a disconnection between young athletes and adults in sports participation expectative as a cause of sports dropout. Petros (2017) state that "Youth Sport Dropout has been an issue for researcher since the early 1970"s". As Gould \& Petlichoff (1970) identify, as cite in Petros (2017) sport dropout prevalence identify $35 \%$. Merkel (2013) confirm the same tendency (35\%) but in adolescence ages (15 years old) the author reports an 80\% dropout rate. Recently, Latorre-Roman, Garcia Pinillos and Lopez Robles (2018) report as high as $96.5 \%$ of sports dropout in a 10 years data recollection (2004-2014) of the best 10 track and field youth athletes of Spain.

Sport dropout must be a major concern for the sports and health community. Studies have connected sport dropout to sedentarism and other health problems. For example Merkel (2013) point put that children 8-18 are replacing outdoors "traditional pickup games" with an average of 7.5 hours of passive-sedentarism activities. In Puerto Rico like in other parts of the world, statistics of child obesity have identified a positive tendency over the past decades.7, 15, 23, 25, 30 Sports has been identified as an alternative for this health problem. Literature has recommended for children and adolescence, good nutrition program, physical activity and low levels of sedentarism, 7, 15, 23, 25, 30

Scientific literature establishes that Sports-based programs can influence positively adolescence or young athletes. ${ }^{15}$ Merkel (2013) states Sports base programs "assist in breaking the vicious cycles of inactivity and 
unhealthy lifestyle". The influence of Grassroots Sports Coaches (GSC) in young athletes has been established (Rutten et al. 2011). Prosocial behaviour (PSB) during adolescence is one important factor. Eisernberg, Fabes and Spinard (2006) cite on Inglés et al (2009) and validated by Hodge, K. and Lonsdale, C. (2011) defined prosocial behaviour as the "voluntary conduct to help others". At this maturation phase (adolescence) conflict conduct emerge or display with negative behaviour as antisocial conduct, aggressiveness, bulling, violence, depression and social anxiety. ${ }^{15}$ Positive conduct must be reinforced to support healthy life skills that can be transfer to other stages of life. Lack to promote prosocial behaviour can lead to health risk conduct in adolescence. ${ }^{1}$ For example, actual scientific literature point out that performing enhancing substance use among young athletes has been documented. Calfee y Fadale (2005) states that "appearance and athletic abilities" are one of the reasons for performing enhancing substance use in young athletes. This kind of conduct can cause serious health problems. ${ }^{17}$ As an example Tzortzi, Lappas, Konstantinidi, Telonaiatis, Tzavara and Behrakis (2018), identify the "increased popularity and use of the water-pipe" smoking, "especially among adolescents and young adults." Sports-Based programs has proven to be an effective to promote healthy lifestyle. $11,12,15,30$

Sports benefits and contribution to participants has been documented by physiologist, physiologist and social sciences researchers. To set the goal for sport participation only focus on the High Performance Level is a narrow vision. Especially if we consider young athletes probability to eventually compete at the elite levels as adults. ${ }^{23}$ Nevertheless if the young participant will eventually follow sport into high performance level or recreational sports. Grassroots sports "praxis" must transform and focus in the participants mind and body benefits as the classic Latin old saying state: "mens sana in corpore sano."

\section{MENS SAN IN CORPORE SANO: BENEFITS OF IN GRASSROOTS SPORTS}

Grassroots Sports participation can benefit young athletes in at least three major areas. They are: Physical, Psychological and Pro Social Behavior. ${ }^{23}$ In terms of physical benefits the impact of sports in the human physiology has been extensively recognize (Lee et al, 2014). Organize sports fi follow the recommended physical activity requirements for children (60 Minutes per day in a daily basis), can be a helpful tool against obesity. ${ }^{23}$

But in addition of physical health, physical activity can bring positive effects to brain functioning. ${ }^{22}$ Study have document how the aerobic exercise interacts with neurotrophic factors to predict cognitive functioning in adolescents. ${ }^{18} \mathrm{~A}$ positive relation between aerobic capacity and cerebral connection (Phase-Locking values) in females adolescence was found by Kamijo et al (2016). Bidzan-Bluma and Lipowska (2018) identify improvement in attention, thinking, language, learning and memory after a systematic review of studies related to this area. This brain positive impact of the physical activity has been related to Academic Success. ${ }^{14,15,16}$

Finally as mention earlier, in addition of body and mind benefits. Physical activity impact the Pro Social Behaviour of sports participant. Researchers as Kirby, Moraczewski, Velonskey \& Redcay (2018) use the term "Social Brain" to explain their research conclusion. Authors identify a positive impact in the "Neural sensitivity" of 40 participants (7 to 13 years old) expose to high social experience (Sports). Findings recognize GRS to impact the human physiology of the participant (Lee, Wong, Lau, Lee, Yau \& So, 2014), but also to influence athlete's prosocial behaviour, Freeman \& Rees (2017). Therefore Sports-Based programs has been designed to promote positive prosocial behaviour in adolescence and young athletes. Scientific literature has an overwhelming evidence of this kind of program in the school scenario. 
The Goldberg and Elliot ATLAS program (Athletes Training \& Learning to Avoid Steroids) was designed for young male athletes involved in all types of school sports. It focuses on "the consequences of drug and athletic supplement use, body image perception, practicing how to refuse a drug offer, media awareness, and sports nutrition and strength training as alternatives to performance enhancing drugs". ATLAS report a drug and alcohol use reduction in 3,200 high school athletes after 5-year of the program. The ATLAS sister program ATHENA design for young women athletes was listed by the Anabolic Steroid Control Act a federal law from the United State of America Congress in 2004.11, 12

Life of an Athlete (LOA) design by John Underwood in 2010 is another sport-base program example that has "reduce student athlete's drinking behaviour through providing comprehensive information on the effects of alcohol on the body and on athletic performance". With an extensive 17,000 student's participation. 30

Recently in the year 2016 the International Olympic Committee develop a second version of the Olympic Values Education Program (OVEP). Originally created by Dr. Deanna L. Binder OVEP toolkit was "designed for learners from 8 to 18 years, often with English as a second language" with "activities for a variety of different age levels and reading abilities." ${ }^{5,16}$ OVEP developers "summarizes over 500 peer-review scientific reports that describe the benefits of physical activity, sports and physical education" in adolescence. 15,16

OVEP is a practical application of Olympic Movement founder ideas. Coubertin as an educator promotes a sports-base program in schools. He "believed that young people needed to train their bodies as well as their minds". ${ }^{15}$, Sports use to disseminate positive values is an essential objective of the Olympic Movement. 8 OVEP promotes a considerable holistic approach to benefits the individuality of the participant, by "challenging and enrich a student's learning experiences" of the participant. 15,16 OVEP "can build resilience and social skills and can have profound effects on the student's life and that of their community" as it state in the OVEP Manual. ${ }^{15,16}$

OVEP implementation has been successful in the school scenario. Sukys, Majauskiene \& Dumciene (2016) implement OVEP for three years. 411 students participate in the Olympic Education program as part of the formal academic curricula. A total of 430 don't have the OVEP program. After the three years prosocial behaviour in the OVEP program participant was significantly high scores than the NO-OVEP group. Considering as Hodge and Lonsdale (2011) establish, that sports in "an important socialization agency, sport has a meaningful role to play in this regard". OVEP is an opportunity to promote a holistic approach in grassroots sports scenario. As Rutten et al. 2011 point out Sport Coaches can develop a "favourable moral atmosphere" that will "positively associated with more prosocial behaviour". Researchers find that "supportive coach-athlete relationships were associated with both less antisocial and more prosocial behaviour in the sports context", Rutten et al. 2011. OVEP could be an alternative to promote PSB if its use formally in the daily training program.

\section{DM: TRANSFORM THE GRASSROOTS SPORT COACHES PROFESSIONAL PRACTICE}

Sports context by itself will not necessarily improve health or pro social behaviour benefits. Social nature of sport provide opportunities for both pro and antisocial behavior. ${ }^{27}$ GSC professional practice must enforce systematically a positive and adequate approach. As mention earlier, consequence of the sport dropout cause by the high performance approach can be detrimental to individual and society in general. "One of the frequently cited reasons for young athletes dropping out of sports programmed is that they stopped having fun". ${ }^{15}$ But are GRS prepare to make the professional practice change and take advantage of sports and their benefits. 
In the US $80 \%$ of baseball coaches in the "little league" and $92 \%$ of high school coaches lack of a formal training. ${ }^{23}$ In Puerto Rico Sport Coaches Certification is less formal than in other countries. Level I Coach Certification consist of 24 contact hours and for the Level II 32 contact hours is require. ${ }^{2}$ In other countries like Cuba Sports Coaches is a 5 year college education career. Knowing the discrepancy levels of coach education in Puerto Rico with other latitudes. ${ }^{2}$ The Sports and Recreation Department promote after any coach certification a mandatory 32 contact hours of professional development every two years. ${ }^{2}$ Due to this professional development requirements for the GSC in Puerto Rico. OVEP can be a useful tool in this coach education process. GSC certify with Olympic Education (OVEP) can offer sports sessions with "best practice" and impact in a positive manner the body and mind of young athletes.

To seek this goal GSC need new forms of sports training has been design. Long-Term Athlete Development (Balyi, I.), Development Model of Sports Participation (Cðtê, J.), Psychological Characteristics of Developing Excellence (Abotts, et al) and Model of Talent Development in Physical Education (Bailey and Morley) are few of them. ${ }^{3}$ In Puerto Rico there is a lack of specific models to help sport coaches oriented their training program. ${ }^{2}$ Therefore base on all the scientific data presented a Three Dimension Model (3DM) is suggested as a holistic approach to grassroots sports training in our cultural context. Base on the Biopsychosocial Model of Development, ${ }^{3}$ 3DM is intended to attend the physical, psychological and social expectative of the young athletes. Basic concept for this 3DM, sports training program will be to have a fun sports training experience, individual development oriented and more focus in skills acquisition and physical conditioning over the competition emphasis.

The first component or Dimension One- Fun, consist of a GSC effort to offer a fun and attractive experience. As Merkel, (2013) state "for the very young athlete the goals of participation are to be active, have fun, and to have a positive sports experience through learning and practice of fundamental skills". In this dimension is an combination of the Balyi LTAD phase one "Fundamentals" and the Siedentops public health goals to "emphasis in an playful activity above all". ${ }^{3}$ With this orientation GSC can attend the participant needs in the "ABC of athletics" (Ability, Balance and Coordination) due to the lack of proper physical education programs in Puerto Rico. With a sports-participation approach to overcome sports dropout and the high levels of sedentarism.

Second, the Dimension Two- Development consist of the Body and Mind component with specific orientation to attend the physical, psychological and social needs of the young athlete. For the physical or body component, GSC will focus in the individual development process of the participant. As Balyi and Way states "the development ages of athletes should be identified and monitored by coaches". The actual practice of periodizing annual programs based on a sports calendar. Will be substitute by identified the Peak Height Velocity (PHV) or the rate of growth of young athletes, to proper determine their LTAD stages. Then, GSC could know better the "window of trainability" to develop speed, skills, flexibility, strength and endurance in the more accurate "sensitive period" of young athletes.

For the psychological and social needs or the mind component part. The integration of the Olympic Education, OVEP is recommended. In our cultural context Olympism is a strong cultural value that will help to ensure emotional, social, and educational and behaviour changes (IOC, 2016). OVEP can be integrated as an intradisciplinary strategy. For example as part of the warmup of at the beginning of the session. Other form can be as an inter-disciplinary strategy were GSC could combine a specific tactical training with the social concept of "teamwork". OVEP can be an independent curriculum, like a recovery session once a week. 
Finally the Dimension Three- Demonstration, is oriented to significant minimize the levels of the competitive focus of the sports participation. Based on Balyi "70:30 Training/Competition Ratio" recommendation for these ages. In this 3DM concept the competition must be considering the acquisition of skills and physical condition over sports results. Programs as IAAF Kids Athletics develop by the International Association of Athletic Federation are the paradigm suggested for the competition part of this model. Created in 2005 this program transform an individual sport to a "Team Event for Children" (https://www.iaaf.org).

\section{FINAL NOTES}

The 3DM is the first effort to formally state a "wake up call" toward the high performance approach in Puerto Rico's grassroots sports. More work must be done to fully develop a model theory and then experimental research projects to evidence this new paradigm. Researches and Institution has been promoting models and strategies based in an extensive scientific literature. Therefore GSC should make a reflective process over their professional practice in youth sports. The traditional pyramidal High Performance Approach and early specialization toward grass roots participant has been identify with one of the sport dropout causes. An holistic approach has been recommended for these young athletes. These sports oriented theory recommend impacting physical, psychological and social needs of the participant. 3DM is a practical application of this theory in the cultural context of Puerto Rico grassroots sports. The model suggest the use of currents tendency such as Balyi's LTAD to accurate develop the physical or body components of young athletes and the Olympic Education (OVEP) for the psychological and social component (Mind). An opportunity to transform the actual Puerto Rico GSC medal approach. To a professional practice paradigm shift base in a holistic approach, much close to a Paidotribo. This sports coach figure of the Ancient Greek, that was responsible of the body and mind preparation of young athletes.

\section{REFERENCES}

1. Acevedo, P., Jorge, J.C., Cruz, A., Amy, E. and Barreto, J. L. (2011) A ten-year assessment of Anabolic Steroid misuse among competitive athletes in Puerto Rico. West Indian Medicine Journal. October; 60(5): 531-535.

2. Alvarez Feliciano, R. (2015) Olympic Weightlifting sport coaches professional practice transformation through Reflective Support Groups between Educators. UMI Dissertation services. UMI No. 3703462. Ann Arbor, Ml.

3. Bailey, R., Collins, D., Ford, P., MacNamara, Á., Toms, M. and Pearce, G. (2010) Participant development in sport: An academic review. Sports Coach UK. Abi Masha, Coachwise Ltd.

4. Balyi, I. \& way, R. The role of monitoring growth in Long-Term Athlete Development. A supplement to: Canadia Sport for Life.

5. Bidzan-Bluma, I. y Lipowska, M. (2018) Physical activity and cognitive functioning of children: A systematic review. International Journal of Enviromental Research and Public Health. https://doi.org/10.3390/ijerph15040800

6. Calfee, R. and Fadale, P. (2005) Popular Ergogenic Drugs and Supplements in Young Athletes.

7. CDC Youth Risk Behavior Surveillance. Commonwealth of Puerto Rico, Mental Health and Antiaddiction Administration, Atlas and Athenas Program Youth Survey. Olympic Training School Salinas, Puerto Rico and Centre for Sports and Health Sciences and Exercise Sciences; 2003-05. https://doi.org/10.17140/droj-1-102

8. Córdova, P. (2017). Educación Olímpica Cuarta Edición. Academia Olímpica de Puerto Rico.

9. Dangi, T. and Witt, P. (2016) Why children/youth drop out of sports? Youth development initiative. Texas A \& M. ydi.tamu.edu. 
10. Freeman, P. and Rees, T. (2017) Coach, Athlete, and Relational Influences on Development Athletes' Attitudes, Intentions, and Willingness to Dope. Final report for the IOC Olympic Studies Centre Advanced Olympic Research Grant Programme 2016/2017 Award.

11. Goldberg, L. and Elliot, D. Athletes Training \& Learning to Avoid Steroids (ATLAS) Coach Manual. Center for Health Promotion Research Oregon Health \& Science University.

12. Goldberg, L. and Elliot, D. Athletes Targeting Healthy Exercise \& Nutrition Alternatives (ATHENA) Coach Manual. Center for Health Promotion Research Oregon Health \& Science University.

13. Hodge, K. and Lonsdale, C. (2011) Prosocial and Antisocial Behavior in Sport: The Role of Coaching Style, Autonomous vs. Controlled Motivation, and Moral Disengagement. Journal of Sport \& Exercise Psychology. 33, 527-547 Human Kinetics, Inc. https://doi.org/10.1123/jsep.33.4.527

14. Inglés, C., Benavides, G., Redondo, J., García, J., Ruiz, C., Estévez, C. y Huescar, E. (2009) Conducta prosocial y rendimiento académico en estudiantes españoles de Educación Secundaria Obligatoria. Anales de Pscicología Volumen 25, No. 1 (Junio) 93-1001. https://doi.org/10.6018/analesps.30.2.148331

15. International Olympic Committee (2016). OVEP: The Fundamentals of Olympic Values Education 2nd Edition. Department of Public Affairs and Social Development through Sport Lausanne, Switzerland.

16. International Olympic Committee (2016) Delivering OVEP A Practical Guide to Olympic Values Education 2nd Edition. Department of Public Affairs and Social Development through Sport Lausanne, Switzerland.

17. Judge, L, Bellar, D., Petersen, J. Lutz, R. Gilreath, E. Simon, L. and Judge, M. (2012) The attitudes and perceptions of adolescent track and field toward PED use. Performance Enhancement and Health. I 75-82. https://doi.org/10.1016/.jpeh.2012.04.002

18. Kamijo K., Takeda, Y, Takai, Y. and Haramura, M. (2016) The relationship between childhood aerobic fitness and brain functional connectivity. Neuroscience letter 632 119-123. https://doi.org/10.1016/j.neulet.2016.08.051

19. Kirby, L. Moraczewski, D., Velonskey, K. \& Redcay, E. (2018) Social network size relates to developmental neural sensitivity to biological motion. Developmental Cognitive Neuroscience. 30 68177. https://doi.org/10.1016/..den.2018.02.012

20. LaBotz, M. and Griesemer, B. (2016) Use of performance enhancing substances Council on sports medicine and fitness American Academy of Pediatrics. Volume 138 , number 1 , July 2016. https://doi.org/10.1542/peds.2016-1300

21. Latorre-Román, P., Garcia Pinillos, F. y López Robles, J. Early sport dropout performance in early years in Young athletes is not related with later success. Retos, 33, 210-212 Federación Española de Docentes de Educación Física. www.retos.org

22. Lee, T., Lawrence Wong, M., Wui-Man Lau, B., Chia-Di Lee, J., Yau, S. and So, K. (2014) Aerobic exercise interacts with neurotroophic factors to predict cognitive functioning in adolescents Psychoneuroendocrinology (2014) 39, 214-224. https://doi.org/10.1016/.jpsyneuen.2013.09.019

23. Merkel, D. (2013) Youth sports: Positive and negative impact on young athletes. Open Access Journal of Sports Medicine. 2013:4 151-160. https://doi.org/10.2147/oajsm.s33556

24. Nicholls, A., Perry, J. Levy, A. Meir, R. Jones, L., Baghurst, T. Sanctuary, C. and Thompson, M. (2015) Coach perceptions of performance enhancement in adolescence: The sport drug control model for adolescent athletes. Performance Enhancement \& Health 3 (2015) 93-101. https://doi.org/10.1016/j.peh.2015.07.001

25. Office of Adolescent Health (2012) Puerto Rico adolescent healthy relationships facts. U. S. Department of Health \& Human Services. http://www.childhealthdata.org/browse/survey?s=2 
26. Petros, L. (2017) The case of Ethiopian Youth Sports Academy Athlete Titunesh Dibaba sports training center. Gaudin B. Kenyan and Ethiopian Athletics- Toward an alternative scientific approach. OSSREA-IRD Editions, Addis Abada. Gaudin B. (ed.). OSSREA-IR Editions.

27. Rutten, E., Schuengel, C., Dirks, E., Stams, G., Biesta, G. and Hoeksma, J. (2011) Predictors of antisocial and prosocial behavior in an adolescent sports contexts. Blackwell Publishing, 9600 Garsington Road, Oxford OX4 2DQ, UK and 350 Main Street, Malden, MA 02148, USA. https://doi.org/10.1111/j.1467-9507.2010.00598.x

28. Sukys, S., Majauskiene, D. and Dumciene, A. (2016): The effects of a three-year integrated Olympic education programme on adolescents' prosocial behaviours, European Journal of Sport Science. https://doi.org/10.1080/17461391.2016.1254280

29. Tzortzi, A., Lappas, A., Kostantididi, E,. Telonaitis, S., Tzavara, C. and Behrakis, P. (2018) Waterpipe smoking among young healty smokers: Immediate effects on breathing patter, respiratory drive and mechanics of tidal breathing. Pneumon- November 2018. https://doi.org/10.1378/chest.1989961

30. Underwood, J. (2014) Life of an Athlete: Program Manual. http://www.lifeofanathlete.us/

\section{(9) $(\Theta \Theta \Theta$}

This work is licensed under a Attribution-NonCommercial-NoDerivatives 4.0 International (CC BY-NC-ND 4.0). 